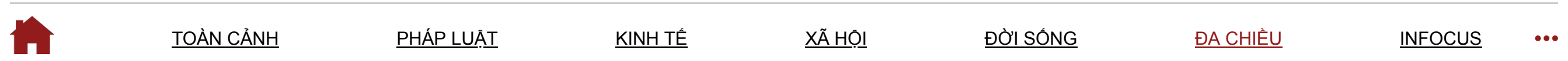

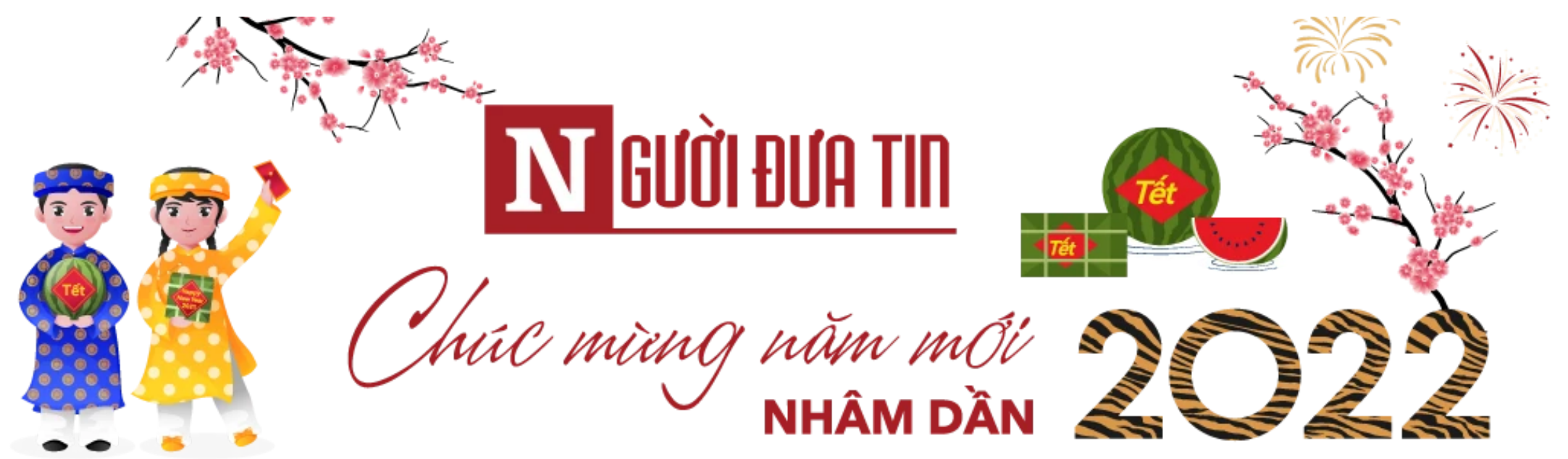

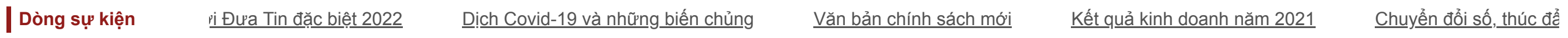

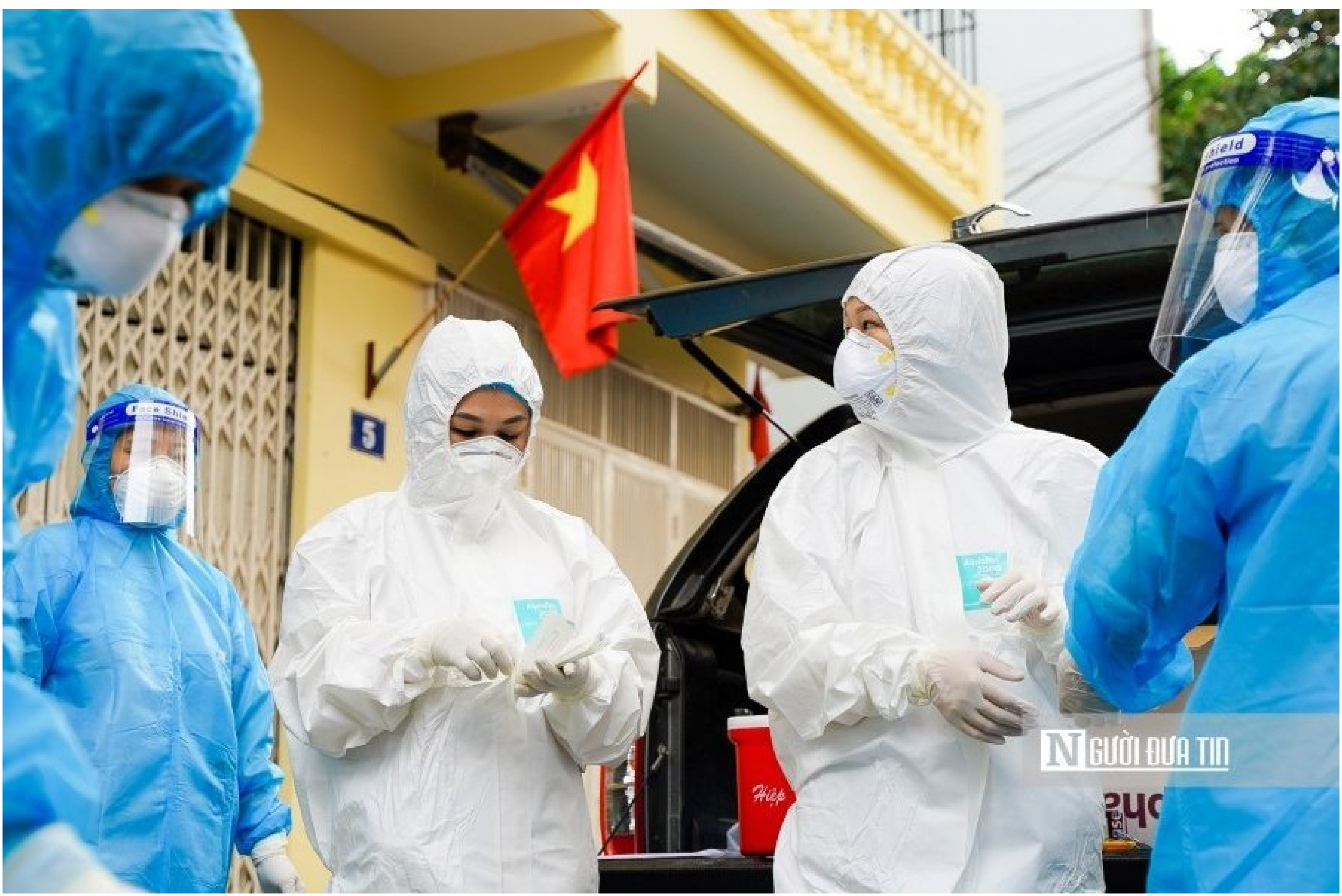

\title{
Vai trò của hệ thống y tế và vắc-xin trong quá trình phòng chống Covid-19
}

Thứ $6,11 / 02 / 2022$ | 15:39

Thích $0 \quad$ Chia sẻ

Việc có hệ thống y tế đảm bảo và lượng bao phủ tiêm vắc-xin cao là chìa khóa để khống chế đại dịch Covid-19

$\mathbf{T}$

rong lịch sử hình thành và phát triển của xã hội loài người, chúng ta đã chứng kiến nhiều cuộc khủng hoảng

nghiêm trọng do các đại dịch gây ra. Bệnh Đậu mùa gây ra cái chết cho $30 \%$ người bị nhiễm và thậm chí là 90\% đối với thổ dân châu Mỹ, hay dịch cúm năm 1918 trong Thế chiến thứ nhất bùng phát và cướp đỉ hơn 20 triệu sinh mạng chỉ trong vòng 3 tháng. Ở thời điểm hiện tại, đại dịch Covid-19 đã và đang gây ra thiệt hại nặng nề về nhân mạng, kinh tế, xã hội cho các quốc gia trên thế giới, với hơn 5 triệu người đã mất do đại dịch. 


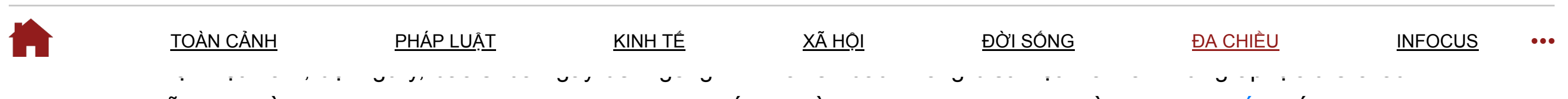

lẫn tinh thần trên vai. Đặc biệt, cường độ làm việc gấp 2-3 lần so với bình thường, điều kiện thời tiết khắc nghiệt, xa gia đình dài ngày, và những áp lực tâm lý do khối lượng công việc quá lớn.

Nhiều trường hợp bác sĩ tuyến đầu đã gặp phải các sang chấn tâm lý và cả những hi sinh, mất mát của chính bản thân họ. Theo PGS.TS Nguyễn Trường Sơn, sự cố gắng này có được là do phần lớn đến từ sự chung sức, xả thân của đội ngũ áo trắng và sự đồng lòng của người dân: "Điều gắn kết các nhân viên y tế, khiến họ trụ vững được là trách nhiệm của người thầy thuốc, là mong muốn cứu được sinh mạng bệnh nhân, là nguyện sớm khống chế được dịch tại Tp.Hồ Chí Minh và các tỉnh, thành miền nam".

Gian nan của các y bác sĩ càng lớn hơn khi tốc độ lây lan nhanh chóng của biến thể Delta đã khiến cho số ca nhiễm vượt quá khả năng chịu tải của hệ thống y tế. Số ca nhiễm tăng nhanh đã gây ra tình trạng quá tải tại các cơ sở y tế, đặc biệt thiếu hụt nguồn nhân lực để kịp thời cứu chữa cho các trường hợp chuyển biến xấu, ngay cả khi nhiều cán bộ, giảng viên, và sinh viên y khoa đã được huy động trên khắp cả nước.

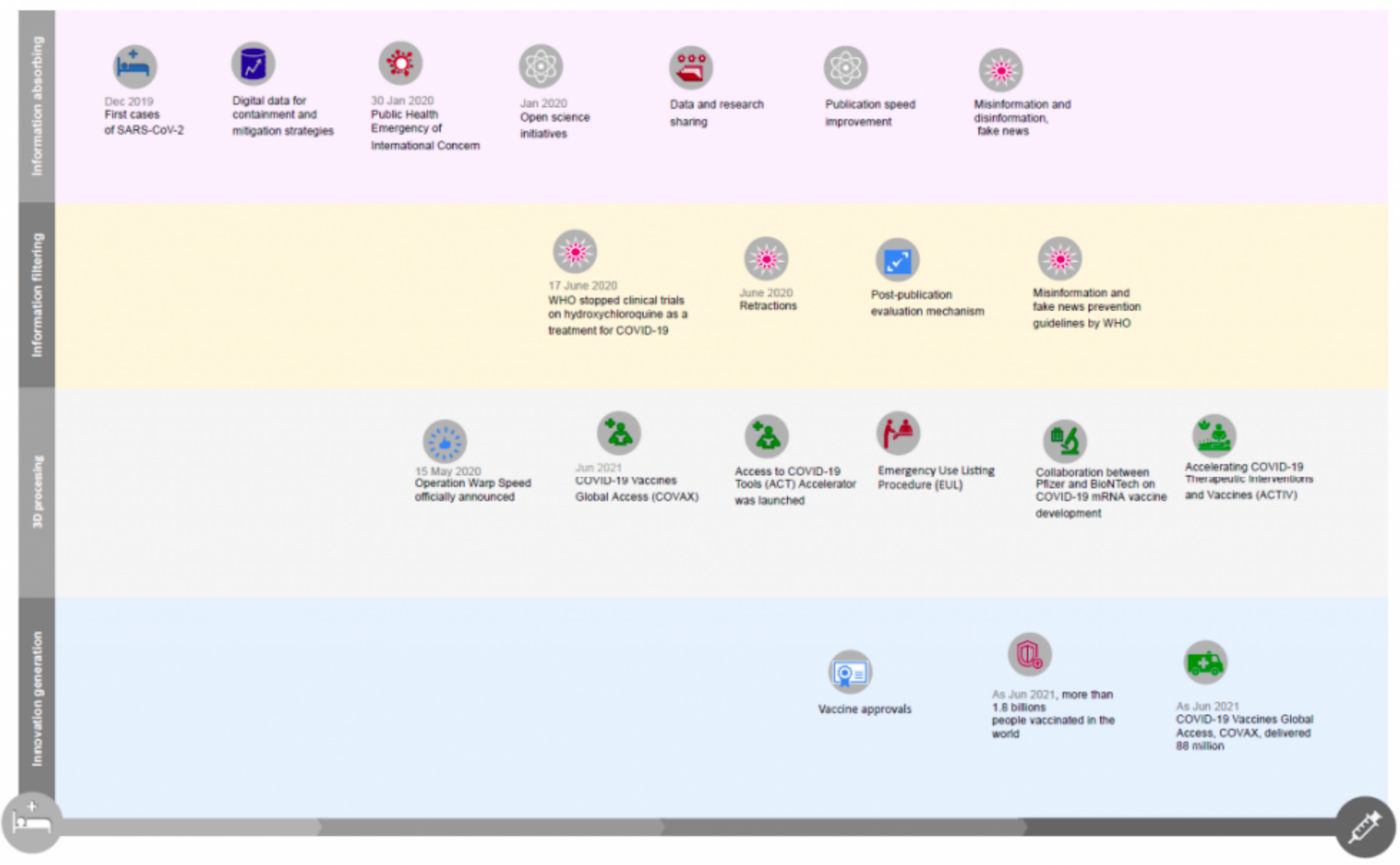

Nhờ có sự xuất hiện của các loại vắc xin mà sự lây lan của dịch ở Việt Nam đã dần được kiểm soát và giảm thiểu sự tổn thất cho toàn xã hội.

Có những giai đoạn, khoảng 40\% lượng bệnh nhân tử vong trong khoảng 72 giờ nhập viện. Bên cạnh Tp.Hồ Chí Minh, các tỉnh và thành phố khác cũng đang chứng kiến sự quá tải của hệ thống $Y$ tế. Mặc dù đội ngũ y tế đã cố gắng hết sức mình, nhưng điều đấy vẫn chưa đủ để dập dịch.

Vắc-xin được xem như là vũ khí hiệu quả nhất để chống lại các đại dịch cho đến hiện nay. Nó giúp phát triển khả năng miễn dịch bằng cách bắt chước tình trạng nhiễm trùng hoặc sự xâm nhập của vi rút. Tuy nhiên, loại nhiễm trùng hoặc loại vi rút này đã được làm yếu và hầu như không đủ khả năng gây bệnh, nhưng nó khiến hệ thống miễn dịch sản sinh các kháng thể và kháng nguyên cần thiết để kháng lại dịch bệnh.

Tuy nhiên để phát triển vắc-xin lại mất rất nhiều thời gian. Trong các đại dịch trước, quá trình phát triển và sản xuất phải hao tốn từ khoảng 4 đến 10 năm. Tuy nhiên, trong đại dịch Covid-19 thì vắc-xin đã được phát triển và sản xuất thành công chỉ trong chưa đầy 1 năm. Các vắc-xin như Sputnik V, Pfizer-BioNTech BNT162b2, Moderna mRNA-1273, AstraZeneca-Oxford AZD1222, CoronaVac đã lần lượt được WHO phê chuẩn và thúc đẩy tiêm chủng trên toàn thế giới. 


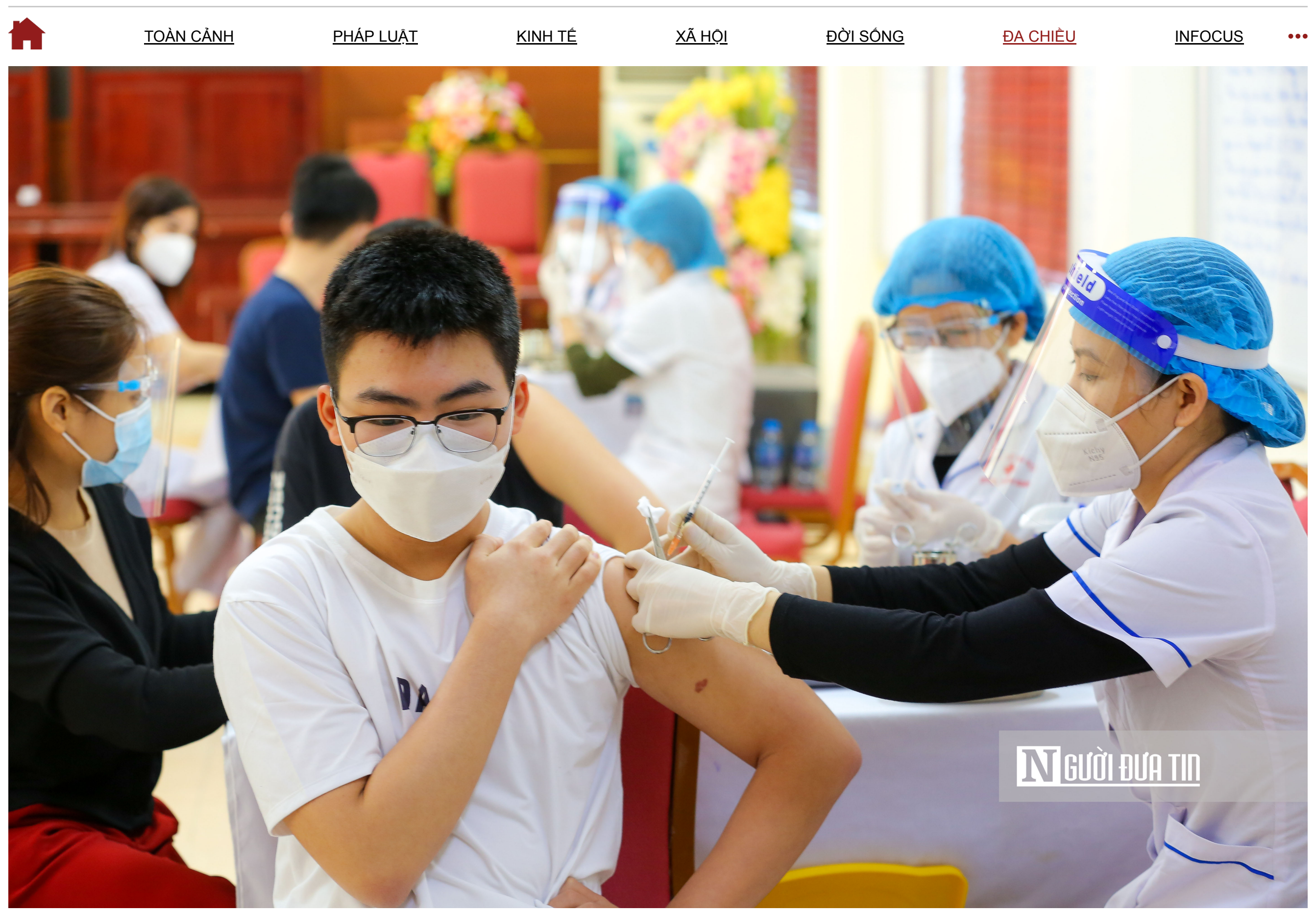

Nhờ có vắc-xin mà dịch bệnh được kiểm soát

Nhờ có sự xuất hiện của các loại vắc-xin này mà sự lây lan của dịch ở Việt Nam đã dần được kiểm soát và giảm thiểu sự tổn thất cho toàn xã hội. Kể từ ngày 8 tháng 3 năm 2021, Việt Nam triển khai tiêm vắc xin AstraZeneca đợt đầu cho nhóm có nguy cơ cao, tổng cộng 100.686 nhân viên y tế và cán bộ công tác xã hội.

Đến ngày 10/7 cùng năm, Thủ tướng Phạm Minh Chính dự Lễ phát động triển khai chiến dịch tiêm chủng vắc-xin phòng Covid-19 trên toàn quốc. Kết quả đạt được tính đến ngày 29/1/2022 thì 180.876.701 mũi tiêm vắc-xin phòng Covid-19 đã được tiêm cho người dân, trong đó hơn $90 \%$ dân số trên 18 tuổi đã được tiêm đủ 2 mũi vắc-xin.

Ghi nhận có 14 tỉnh/thành phố đang tiến hành tiêm 11.779.039 liều vắc-xin cho nhóm trẻ em từ 12-17 tuổi, trong đó 4.327.365 trẻ được tiêm đủ 2 mũi vắc-xin. Kinh tế và hoạt động xã hội đã dần được mở cửa lại bình thường, nhưng số ca nhiễm thì vẫn trong tầm kiểm soát của hệ thống y tế.

Mặc dù vắc-xin Covid-19 đã được tiêm chủng rộng khắp, nhưng vẫn còn nhiều câu hỏi về việc làm cách nào mà vắc-xin đã được phát triển và sản xuất nhanh chóng.

Mới đây, nhóm nghiên cứu tới từ Trung tâm nghiên cứu Xã hội liên ngành (đại học Phenikaa) và Trung tâm Nghiên cứu Kinh tế Phát triển (Đại học Quốc gia Hà Nội) đã sử dụng hệ thống lý thuyết serendipity-mindsponge-3D (SM3D) để lý giải vì sao vắc-xin ngừa Covid-19 lại có thể phát triển và sản xuất thành công trong thời gian ngắn.

Bài nghiên cứu có tên "Covid-19 vaccines production and societal immunization under the serendipity mindsponge3D knowledge management theory and conceptual framework" (Tạm dịch: Lý giải quá trình sản xuất và tiêm chủng vắc xin Covid-19 dựa trên hệ thống lý thuyết quản trị tri thức serendipity-mindsponge-3D) đã được đăng tải trên Tạp chí khoa học Humanities and Social Sciences Communications, tập san thuần túy về KHXH\&NV duy nhất trong Nature Portfolio.

Nhóm tác giả vận dung hệ thống lý thuyết quản trị kiến thức serendipity-mindsponge-3D (SM3D) để lý giải quá trình đánh giá, xử lý, và vận dụng thông tin toàn cầu nhằm đẩy nhanh quá trình phát triển vắc xin ngừa Covid-19. 
trị và cơ chế sáng tạo. Việc xuất bản thành công hệ thống lý thuyết SM3D trên tạp chí Humanities and Social Sciences Communications có thể được xem như một bước tiến lớn của khoa học Việt Nam trong cộng đồng khoa học quốc tế, bởi vì đây là tạp chí có các tiêu chí chọn lọc và bình duyệt cực kỳ khắt khe.

Một số nguyên lý cũng được đưa ra để tối ưu hoá việc nghiên cứu và sản xuất vắc-xin dựa trên cơ chế sáng tạo 3D:

Cần có sự tham gia bởi các chuyên gia và tổ chức uy tín để đánh giá và xử lý nguồn cung cấp thông tin; Sự kết hợp chặt chẽ giữa các chuyên gia và tổ chức uy tín;

Và quá trình hợp tác này cần được đảm bảo sự liên tục và kỷ luật chặt chẽ cho đến khi sản phẩm sáng tạo hoặc giải quyết được vấn đề (lúc vắc-xin Covid-19 ra đời).

Nhóm tác giả đồng thời cũng đề cập việc sản xuất vắc-xin không đồng nghĩa với việc giải quyết được vấn đề, mà quá trình sáng tạo và quản trị kiến thức này cần được tiếp tục và kéo dài để giải quyết 3 vấn đề sau: Thứ nhất, loại vi-rút này có tính chất dễ gây đột biến và gây ra các biến chủng, chẳng hạn như Delta và Omicron

Thứ hai, việc lưỡng lự trong việc tiêm vắc-xin của một số cá nhân có thể để lại hậu quả nghiêm trọng cho sức khoẻ, tính mạng của cá nhân và toàn xã hội (ví dụ như tạo điều kiện để các biến chủng xuất hiện). Do đó, các biện pháp và chính sách hợp lý để giảm thiểu làn sóng "chống vắc xin" là cần thiết để đạt được bình thường hoá xã hội. Những làn sóng chống vắc xin tại Nga và Úc có thể xem như các ví dụ điển hình.

Thứ ba, việc phân bổ vắc-xin cần được đồng đều, tránh bất bình đẳng giữa các quốc gia, dân tộc, tôn giáo và các nhóm người thiểu số. Quá trình sáng tạo được tóm tắt trong hình dưới.

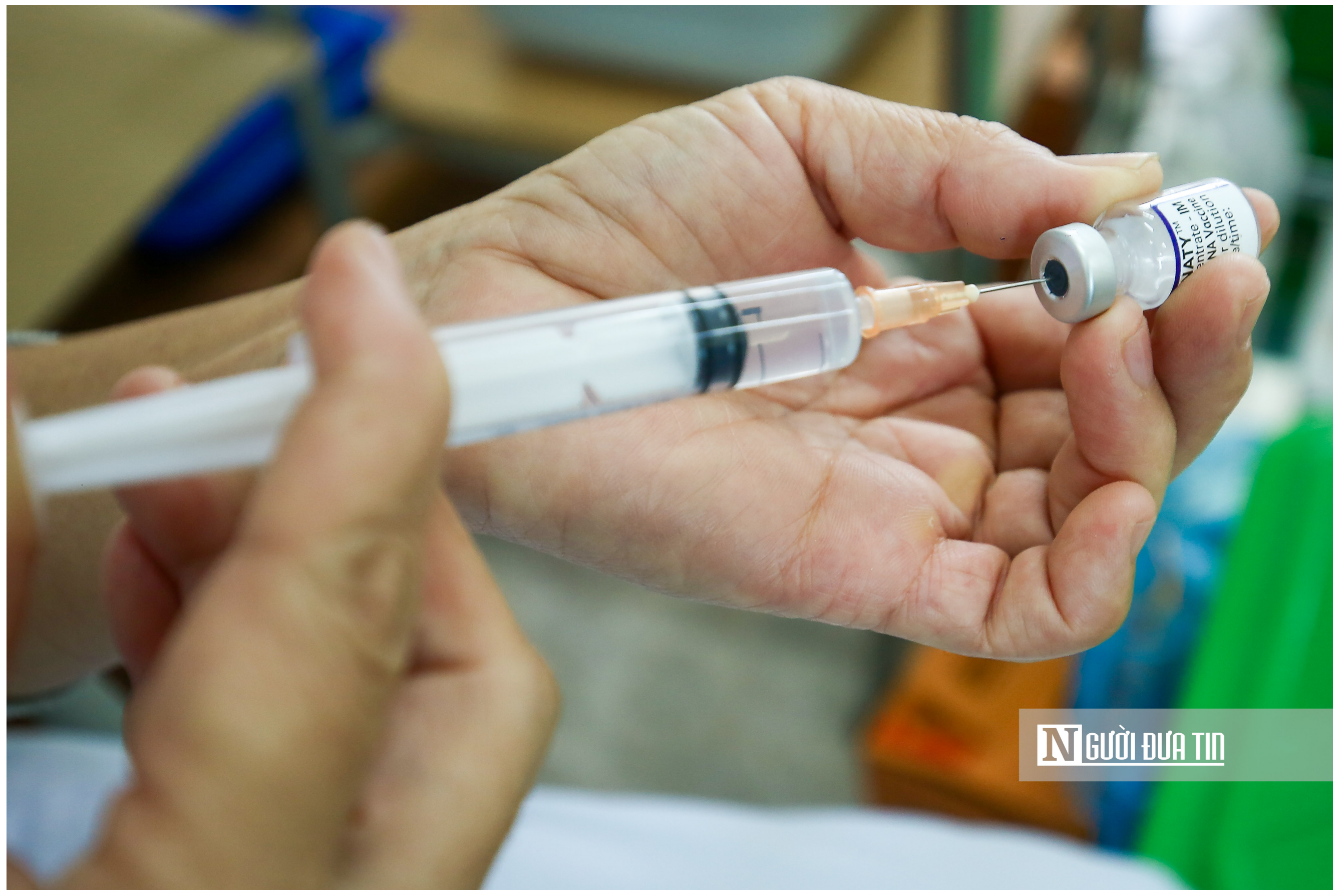

Việc phân bổ vắc-xin phải đồng đều giữa các quốc gia

Qua đó có thể thấy, để vượt qua khó khăn ảnh hưởng đến sinh mạng người dân như đại dịch Covid-19, chúng ta không chỉ cần sự cố gắng hết mình của các $\mathrm{y}$, bác sĩ ở nơi tuyến đầu mà còn cần những đột phá về khoa học và công nghệ, như vắc xin Covid-19. 
ĐỜI SÓNG

ĐA CHIËU

INFOCUS $\quad \cdots$

mệt mỏi của các chuyên gia nghiên cứu, tổ chức uy tín, và các chính phủ. Nếu không có quá trình đầu tư lâu dài và bài bản vào nền tảng nghiên cứu khoa học thì có thể thành công này đã không xuất hiện.

Mặc dù sự xuất hiện của vắc-xin giúp cho chúng ta có thêm sức mạnh để chiến đấu chống lại Covid-19, nhưng còn đó các biến chủng mới kháng vắc xin và nguy cơ xảy ra đại dịch mới nguy hiểm hơn.

Cho nên, việc đầu tư vào nghiên cứu khoa học tự nhiên và xã hội là rất cấp thiết, vì các ứng dụng và đột phá trong khoa học có thể giúp chúng ta vượt qua khó khăn mà sức người thuần túy không thể ứng phó .

\section{Nguyễn Quang Lộc, SP Jain School of Global Management, New South Wales 2141, Australia}

Nguồn tham khảo:

1. Lê, T., Lam, T., \& Duy, M. (2021). Ngành y tế đã làm việc bằng $200 \%$ sức lực. Nhân Dân. Trích xuất từ: https://special.nhandan.vn/thutruong_covid19tphcm/index.html

2. Vuong, Q.-H., et al. (2022). Covid-19 vaccines production and societal immunization under the serendipitymindsponge-3D knowledge management theory and conceptual framework. Humanities and Social Sciences Communications, 9, 22.

3. Vuong, Q.-H. (2018). The (ir) rational consideration of the cost of science in transition economies. Nature Human Behaviour, 2, 5 .

Tag: nghiên cứu đại dịch vắc-xin

Bạn nghĩ gì về tin này?

Gửi bình luận

Đăng nhập

Bình luận tiêu biểu (0)

Sắp xếp theo lượt thích | Sắp xếp theo ngày

Chưa có bình luận. Hãy là người đầu tiên bình luận bài viết này. 